\author{
OAK RIDGE NATIONAL LABORATORY \\ OPERATED OY \\ UNION CARBIDE CORPORATION \\ NUCLEAR DIVISION \\ CANHOH \\ POST OFFICE BOX $X$ \\ OAK RIDGE, TENNESSEE 37830
}

RDT STANDARDS TRANSMITTAL

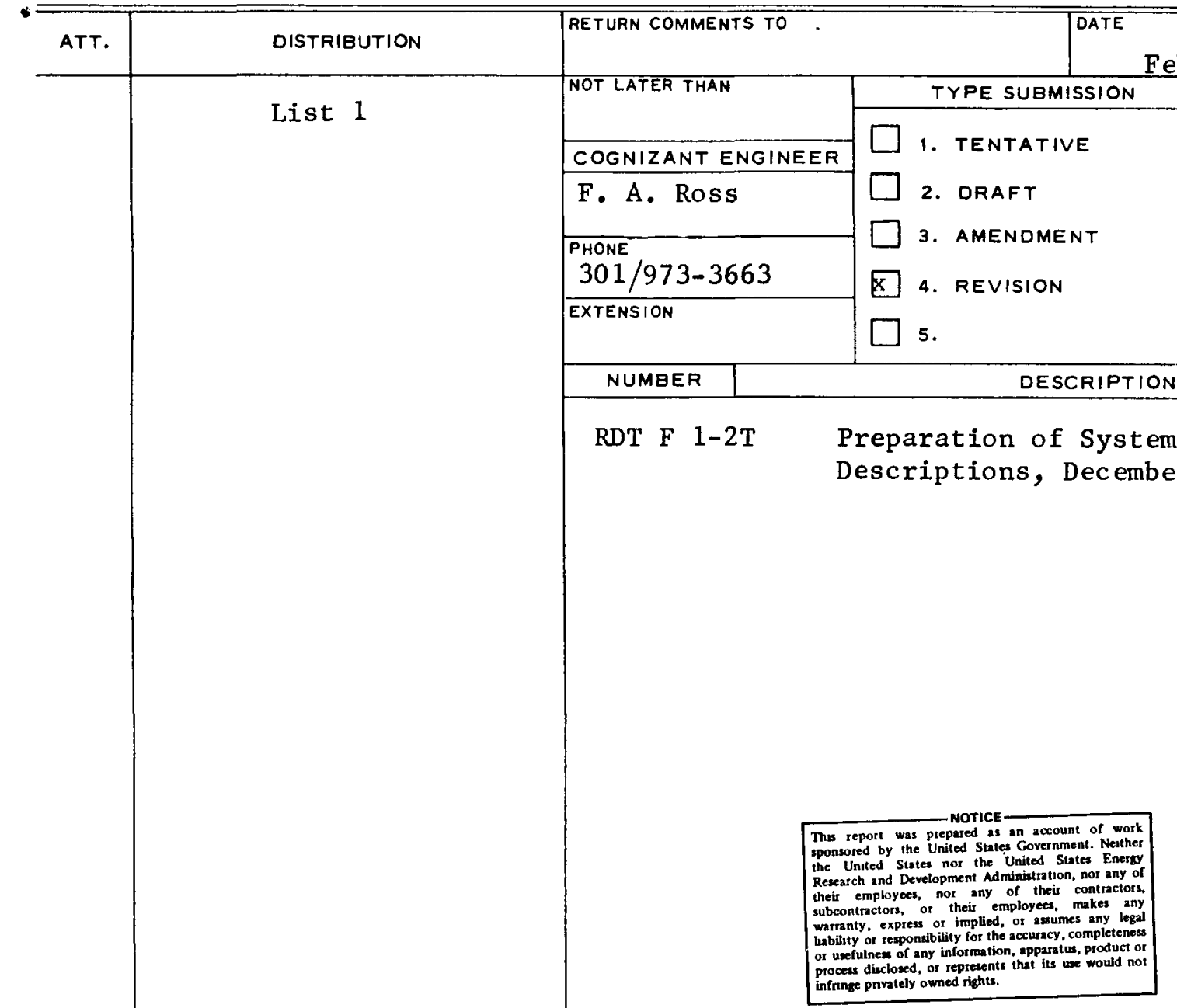

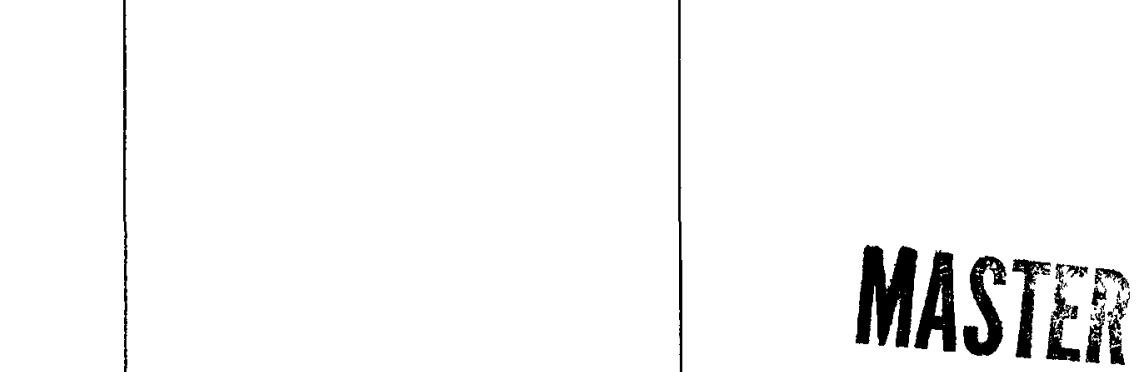

Feterse ro Armouncement inclear Soienca Abstracts 


\section{DISCLAIMER}

This report was prepared as an account of work sponsored by an agency of the United States Government. Neither the United States Government nor any agency Thereof, nor any of their employees, makes any warranty, express or implied, or assumes any legal liability or responsibility for the accuracy, completeness, or usefulness of any information, apparatus, product, or process disclosed, or represents that its use would not infringe privately owned rights. Reference herein to any specific commercial product, process, or service by trade name, trademark, manufacturer, or otherwise does not necessarily constitute or imply its endorsement, recommendation, or favoring by the United States Government or any agency thereof. The views and opinions of authors expressed herein do not necessarily state or reflect those of the United States Government or any agency thereof. 


\section{DISCLAIMER}

Portions of this document may be illegible in electronic image products. Images are produced from the best available original document. 


\section{RDT F $1-2 T$}

Supersedes

RDT F 1-2T, March 1972

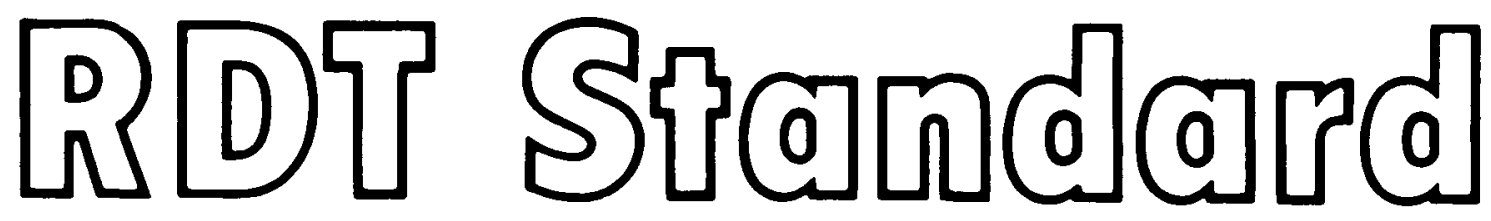

PREPARATION OF SYSTEM

DESIGN DESCRIPTIONS

DECEMBER 1975

\footnotetext{
Any further distribution by any holder of this document or of the data therein to third parties representing foreign interests, foreign governments, foreign companies, and foreign subsidiaries or foreign divisions of U.S. companies should be coordinated with the Director, Division of Reactor Development and Demonstration, U. S. Energy Research and Development Administration.

U.S. EEEPGY RESEARCH AND DEVELOPMENT AD"INISTRATION DIVISION OF REACTOR DEVELOPMENT AND DEMDNSTRATION
} 
Send copy and distribution inquiries to:

ROT Standards Office

Oak Ridge National Laboratory

Building 1000, Room 138-A

P. O. Box $X$

Oak Ridge, Tennessee 37830

Printed in the United States of America

USERDA Technical Information Center; Oak Ridge, Tennessee 
This standard supersedes the March 1972 issue of RDT F 1-2T and incorporates those changes to that issue of the standard that were approved and published as Amendment 1 and those changes that were approved for publication in this revision. These changes are identified by the following notations:
A1 Amendment 1, May 1973
C Change approved December 1975
D Deletion approved December 1975
N Addition approved December 1975

Editorial changes that were made during preparation of this revision are not identified. 


\section{RDT STANDARD}

U.S. ENERGY RESEARCH AND DEVELOPMENT ADMINISTRATION DIVISION OF REACTOR DEVELOPMENT AND DEMONSTRATION
RDT F 1-2T

DATE December 1975

PAGE 1 OF $i$

PREPARATION OF SYSTEM DESIGN DESCRIPTIONS

\section{TABLE OF CONTENTS}

Page

1. SCOPE

2. PURPOSE OF SYSTEM DESIGN DESCRIPTIONS 1

2.1 General

2.2 Scope and Use

2.3 Use for Design Control

3. APPLICATION OF SYSTEM DESIGN DESCRIPTIONS

3.1 Reactor Plants

3.2 Test Facilities

3.3 Responsibility for Preparation and Updating

4. CONTENT OF SYSTEM DESIGN DESCRIPTIONS 4

4.1 General 4

4.2 Summary 4

4.3 Functions and Design Requirements (Section. 1) 4

4.4 Design Description (Section 2) 6

4.5 System Limitations, Set Points, and Precautions 9 (Section 3)

4.6 Operation (Section 4) 9

4.7 Casualty Events and Recovery Procedures 11 (Section 5)

4.8 Maintenance (Section 6) 11

4.9 Appendixes 13

5. CONTENT OF OVERALL PLANT DESIGN DESCRIPTION 14

$\begin{array}{lll}5.1 \text { Content } & 14\end{array}$

APPENDIX A - DETAILED OUTLINE FOR HEAT TRANSPORT SYSTEM 16

APPENDIX B - DETAILED OUTLINE OF SECTIONS 1 AND 2 FOR REACTOR SYSTEM 


\section{SCOPE}

This standard prescribes the purpose, scope, organization, and content of system design descriptions (SDD's), in order to promulgate a unified approach to their preparation and use by a project as the principal means to establish, describe, and control the individual system designs from conception and throughout the lifetime of the system.

\section{PURPOSE OF SYSTEM DESIGN DESCRIPTIONS}

2.1 General. SDD's are comprehensive technical documents that specifically and completely define the design, including operation, maintenance, and reliability requirements, of individual systems which comprise a nuclear power plant or test facility. SDD's are prepared and maintained current by the responsible system designer and are the principal means of system design definition and control common to the designer and the other participating organizations responsible for the project.

The SDD's provide the system requirements for the preparation of standards and specifications for the individual components comprising those systems; for the development of the system configuration and arrangement within the plant or facility; and for the preparation of operating and maintenance procedures, reliability requirements, and required safety documentation. Thus, the SDD's form a focal point for assessment and control of the progress of the system design by the project management.

2.2 Scope and Use. The SDD presents the specific system design requirements and shows how these requirements are satisfied by the design. It includes the design requirements and a complete description of the system design features, such as flow path and performance, system operating and design parameters, system arrangement, component principal design features, and system operation and maintenance. The SDD generates the principal component requirements for preparation of component specifications. The description of system operation and maintenance in the SDD is sufficiently explicit to confirm that the system can be operated to meet the design requirements; it will also provide the basis for preparation of the overall plant and individual system operating procedures, maintenance procedures, test procedures, and casualty recovery procedures. The system arrangement, maintenance, and inspection requirements as described in the SDD are the technical bases for engineering the arrangement of that system within the overall plant or facility. The SDD describes the required supporting services which impose design functions and requirements on interfacing systems. 
The SDD also identifies the level of quality assurance, realiabilitycritical items, codes, and standards to be applied to system and component design, construction, testing, and operation. The SDD also provides the design basis used for preparation of safety analysis reports and technical specifications.

While the SDD describes the system design in progressively greater detail as the design is evolved, it is not an historical document. With its associated appendixes and references, the SDD provides the basis for the design selected. However, it does not trace the design alternatives that may have been considered and ultimately rejected in favor of the selected design, and it does not describe the development program that may be necessary to establish or verify the design; this essential information is provided by separate evaluations, trade studies, or program documents as appropriate to particular aspects of the design.

2.3 Use for Design Control. The SDD is used to control the system design, and therefore implementation of the system design and related project activities, such as component procurement, proceed only in conformance with approved SDD's. The initial SDD and all changes to the SDD are prepared by the cognizant system designed and are approved in accordance with procedures defined by the particular project. Each project shall have suitable procedures to assure that SDD approval and change control are effectively implemented according to the needs of the project.

Effective control of the system design evolution is accomplished by maintaining the SDD technically current. Proposed changes to an SDD are accompanied by suitable technical justification, and the specific changes from the previously approved issue of the SDD are clearly identified. When the approved changes to the SDD are issued, the locations of the changes to the SDD are indicated in the margin of the text. Any system design change in an SDD is reflected simultaneously in revision of all sections of the SDD to which it applies. Where a drawing is an integral part of the SDD, changes to that drawing are processed as an SDD change.

It is important that the SDD present a complete and accurate description of the design. Therefore, particularly in drawings, any feature that is not recommended for approval because of existing uncertainties is specifically identified by suitable "hold" markings. In addition, the text of the SDD clearly identifies any descriptive information that is not current design and is not recommended to be fully approved.

\section{APPLICATION OF SYSTEM DESIGN DESCRIPTIONS}

3.1 Reactor Plants. An SDD is usually applied to a set of components that perform in a coordinated fashion to produce a desired function. An SDD should be prepared for each reactor plant system, with the exception of those utilities, structures, and site service or 
process systems which are not contiguous to the plant or are not a direct functional part of plant operation. SDD's are required for the individual fluid systems, instrumentation and control systems, and electrical systems. The reactor vessel and head cavity, the reactor core and internals, and the fuel handling system should be covered by separate SDD's. The reactor plant overall arrangement, configuration, and structures, including the containment design, should be covered by SDD's. Some SDD's for complex systems, such as reactor refueling or process monitoring and control, may be arranged in units corresponding to individual subsystems. In such cases, each unit shall contain all the sections of an SDD and may be prepared and submitted for approval separately.

Al1 SDD's shall interface to cover the complete plant, and there should be no duplication of SDD coverage. However, in addition to these individual SDD's, an overall plant design description (OPDD) shall be prepared to provide an overview of the relationship and interfaces of al1 the systems and facilities which comprise the plant.

Each profect should reach agreement at the inception of the project design phase on the specific SDD's to be prepared. For this purpose, an index should be prepared to define the individual systems or grouping of subsystems to be covered by each SDD which will best meet the needs of the specific project.

3.2 Test Facilities. For purposes of SDD preparation, major test facilities should be treated in a manner similar to reactor plants, as described in 3.1. The complexity of the facility will determine the number of SDD's needed for adequate design description. For small test facilities only one SDD may be required if it will provide adequate design description.

3.3 Responsibility for Preparation and Updating. SDD's are prepared by the cognizant system design organization. Within that organization, the engineer assigned system design responsibility also should be responsible for the preparation and timely revision of the SDD for that system.

The initial issue of an SDD is prepared as a primary part of the conceptual design activity to enable project participants to reach agreement on a conceptual system design at the earliest possible date. As the design work progresses, more detalled design information is provided by the system designer through timely changes to the SDD's. Thus, the content of the SDD will progressively change throughout the system design process, construction, and acceptance testing. Following completion of the plant or facility design, construction, and acceptance testing, project assignments may require that the responsibility for maintaining SDD's current be transferred from the design organization to the cognizant engineering activity of the responsible plant operating organization. The SDD shall be maintained current throughout the operating life of the system. 


\title{
4. CONTENT OF SYSTEM DESIGN DESCRIPTIONS
}

The information appearing in 4.1 through 4.9 applies to the scope and content of individual SDD's, whereas the content of the OPDD is outlined in section 5 .

4.1 General. The SDD is a comprehensive design document that meets the purpose and application requirements discussed in Sections 2 and 3 of this standard. SDD's should conform to the following basic outline, although this format may be varied if necessary to adequately describe a particular system:

\author{
Summary \\ Section 1 Functions and Design Requirements \\ Section 2 Design Description \\ Section 3 System Limitations, Set Points, and Precautions \\ Section 4 Operation \\ Section 5 Casualty Events and Recovery Procedures \\ Section 6 Maintenance \\ Appendixes
}

The following subsections describe the content of each section of the SDD in more detail, using an outline developed for a reactor plant fluid system. However, the breakdown of subsections within each section of the SDD may be varied, depending on the particular type of system, in order to provide the most effective, complete, and logical presentation sequence of design information for that system with a minimum of redundant information.

An example of a typical outline for a sodium cooled reactor heat transport SDD is included in Appendix A. For comparison and to illustrate the intended flexibility of the SDD format to accommodate different types of systems, an outline of Sections 1 and 2 for a sodium cooled reactor SDD is shown in Appendix B. The latter SDD is organized somewhat differently from the former SDD to better describe the functional relationship of component and system elements which comprise the reactor system. This is accomplished by providing both system and component subsections in the design requirements and design description sections.

4.2 Summary. This section contains a brief summary of the functions and scope of the system, and normally should not exceed one page length.

4.3 Functions and Design Requirements (Section 1). This section contains the specific functions and design requirements to be satisfied by the system. These design requirements should be in accordance with the overall project technical requirements. However, the technical basis for the specific requirements should be contained in supporting documents and not included in the SDD. Typical content of the various subsections of Section 1 is provided in the following discussion. 
4.3.1 Functions. The individual functions of the system should be concisely and specifically stated, preferably in itemized format. This subsection should be less than one page in length.

4.3.2 Design Requirements. The subsections which follow the system functions cover the system design requirements and are combined into common groups such as process requirements, structural requirements, etc. The information should be specific, definitive, and concise; generalities and platitudes should be avoided (e.g., that the system is to be reliable or safe). A statement similar to that shown in Example 1 should be given rather than stating "activation of secondary sodium should be minimized."

Radioactivity in the secondary loops shall be limited to $4 \times 10^{-10}$ curies $/ \mathrm{cm}^{3}(0.2 \mathrm{mrem} / \mathrm{h})$ by shielding and layout directed toward minimizing the activation of secondary sodium.

\section{Example 1}

As a minimum, the following subsections should be included, but the order of these subsections may be changed and other subsections may be added to completely characterize a particular system.

\subsubsection{Process Requirements (or Operational Requirements).} This should include items such as thermal power rating, operating temperatures, required operating modes, and requirements associated with unique functions of the system (e.g., decay heat removal for a reactor heat transport system).

4.3.2.2 Structural Requirements. This should include such design requirements as design pressure and temperature, design thermal transients, seismic design requirements, load combinations, design for natural phenomena such as wind loads, basic materials for construction, etc. The specific values generally should be directly included in the SDD, but may be referenced where extensive information is necessary which would impair the continuity of the SDD by direct incorporation (e.g., design thermal transient curves, or seismic response spectra).

4.3.2.3 System Configuration and Essential Features. This should include requirements for the unique features, arrangements, constraints, etc., that physically characterize the system configuration and its location. For a reactor heat transport system, as an example, this might include the fact that there should be three primary loops, each with an associated secondary loop; that individual loop isolating valves are to be provided; or that a hot leg (or cold leg) primary pump is to be provided.

4.3.2.4 Maintenance. This should include items such as access and space requirements for contact (hands-on) maintenance, 
shielding requirements and maximum allowable radiation levels in various areas for maintenance, and other specific provisions for maintenance.

4.3.2.5 Surveillance and In-Service Inspection. This should include items such as required access provisions and periodic inspection requirements for vessels and piping, monitoring instrumentation for specific components, etc.

4.3.2.6 Instrumentation and Control. This should include instrumentation and control requirements for system operation and control with identification of those specific access, redundancy, and calibration requirements or constraints that apply.

4.3.2.7 Interfacing Systems. This should include a list of the functions and services that are to be provided by interfacing systems.

4.3.2.8 Quality Assurance. The quality assurance requirements for design, construction, test, and operation of the system should be defined.

4.3.2.9 Codes and Standards. A list of codes and standards, including $\mathrm{RDT}$ standards, to be applied to the system design, construction, and operation and to the individual components of that system should be included.

\subsubsection{Reliability Assurance. Reliability requirements} shall be included for systems, subsystems, and components which are identified as reliability-critical items. These requirements should be stated as specifically as practical for the particular system involved (e.g., 100 percent redundant capacity is to be provided for the emergency feedwater supply to the steam generators.)

4.4 Design Description (Section 2). This section contains a summary description and a detailed description of the system and its components, the system arrangement, and the system performance characteristics. The design description is of sufficient depth to show how the design satisfies the system functions and design requirements. Those items normally included in this section of the SDD are described in more detail in the following subsections.

4.4.1 Summary. The summary gives a brief general description of the system and its configuration. The relationship of the system to the entire reactor plant or facility should be given, including plot plans if appropriate.

4.4.2 Detailed System Description. This subsection contains a detailed discussion of the system design. The system flow paths for its various operating modes should be completely described to clearly show how the system functions and how it satisfies the design requirements. In this description, the operating and design data should be included, 
and reference should be made to the system process and instrument drawing, and to other drawings needed for effective design description. A portion of the description of the flow path for a sodium heat transport loop follows as Example 2 .

Heated sodium flows from the reactor outlet nozzle through the hot leg isolation valve to the suction of a centrifugal, free surface pump. Sodium from the pump discharge is circulated to the shell side of the intermediate heat exchanger where the heat is transferred to secondary sodium. From the intermediate heat exchanger outlet, the primary sodium flows through a check valve, a cold leg isolation valve and then to the reactor vessel inlet and through the reactor, thus completing the flow cycle. Sodium flow rate is measured by a permanent magnet flowmeter located downstream of the IHX outlet and is adjustable by variable-speed pump drives.

Example 2

Specific design features and sizing parameters should be included in the text or by tabulations and drawings (e.g., the volume of coolant in individual loops should be included when describing a heat transport system). Examples 3 and 4 are excerpts from a sodium cooled reactor heat transport SDD and are representative of specific design information to be included in this section.

The size of the 28-inch-diameter reactor outlet pipe has been governed mainly by the frictional pressure losses in this line which, with the frictional head loss through the hot leg isolation valve, determines the drawdown (sodium level change) in the primary pump.

Example 3

Table 2.1 shows the allocated pressure drop for the primary piping system consistent with the allocations for the components and the reactor and the maximum TDH limitation of 500 feet for the single stage pump.

Example 4

4.4.3 System Performance Characteristics. This subsection provides the system performance characteristics under the varlous normal and infrequent operating modes and off-normal operating conditions. Typical items to be included in this section for a heat transport system are the system head-flow characteristic curves, natural circulation 
performance curves, and the system hydraulic profile. Example 5 is an excerpt from a sodium heat transport SDD and provides a discussion of system performance to minimize thermal transients to the reactor when the reactor is scrammed.

The main drive to the primary and secondary pumps and to the heat dump fans are immediately tripped to minimize the rate of change of system temperatures. The pumps coast-down to pony motor operation as shown in Figures $2-5$ and 2-6. Changeover from main to pony motor drive is automatic. The heat dump inlet air flow control vanes are also automatically closed to prevent excess heat rejection following the scram. The thermal transients at reactor core outlet are considerably attenuated before reaching the reactor vessel outlet piping by the mixing and heat capacity of the large volume of sodium in the reactor outlet plenum.

\section{Example 5}

4.4.4 System Arrangement. This section includes a description of the system arrangement with reference to the included system drawings. The system piping arrangement and the location of operating stations should be described. Such features as the provision of inerted cells to house the system, the means and conditions of access, and any special provisions for maintenance access or inspection should be included.

4.4.5 Component Design Descriptions. Description of the individual system components should be included in this section. The design parameters and the principal design features of each component should be identified and component operation should be described. Simplified outline drawings of the components should be included in the text for improved understanding of the component design and operation. Detailed component drawings may be included in the list of references. Component data sheets may be included in this section or reference made to an appendix for detailed information, such as valve, piping, and instrument lists, etc.

Alignment, tolerances, and stackup of system components important to the system design should be identified in this section for SDD's which cover the reactor. Analyses and drawings that show how the system design satisfies these dimensional interfaces should be included as a reference or appendix to the SDD.

4.4.6 Instrumentation and Control. This section should include a description of the system instrumentation, controls, and interlocks. Such controls and interlocks as variable speed control of a primary coolant pump or primary pump trip on a reactor scram should be covered. The instrumentation associated with operation of the system should be 
defined, including the type, range, accuracy, set point, and location of sensor and instrument readout, with appropriate reference to the process and instrument drawing. Instrumentation readout and control location should be clearly identifled (e.g., in the control room, or at specified local control stations). Instrument and control component performance information should be provided when it will aid in understanding the system design, operation, and maintenance. Reference should be made to the instrumentation list which itemizes the instrument sensing elements, type, range, set point, whether indicating control or alarm, and readout location. This list is included as an appendix to the SDD as noted in 4.9 .4 .

4.4.7 System Interfaces. This section of the SDD should identify and describe the system interfaces with other systems. These interfaces impose functional and physical requirements on each of these associated systems, and identification in the SDD facilitates control of these system interfaces. This section also should indicate how the system design satisfies the system interfaces that impose functional requirements on the subject system. The SDD's may have detailed lists of system interfaces in tabular form, and these lists may be included in an appendix.

4.5 System Limitations, Set Points, and Precautions (Section 3). This section of the SDD should provide a consolidated 1ist of system limitations, set points, and precautions that will provide a better understanding of system operation, response to casualties, and maintenance which are described in later sections of the SDD. Under operating limits, the SDD should include in summary form the high and low limits for all controlled variables. The dead band and overshoot for both manual and automatic control also should be included. Appropriate limits, such as relief valve settings, maximum liquid level, etc., should be identifled. The set points or nominal settings for automatic and manual controls for all anticipated operating modes should be provided.

This section should provide precautions to be observed by operations and maintenance personnel. Design precautions such as interlocks and alarms also should be included. The system status checks needed for changing set points should be defined. Where appropriate, detailed tabular lists may be included in an appendix of the SDD and referenced in this section.

4.6 Operation (Section 4). This section includes subsections covering outlines of all system operating procedures. These subsections should provide detail to confirm that the design provides for the required modes of system operation and also should be a sufficient basis for preparation of detalled operating procedures. There should be a direct relationship between the individual operating procedure outlined in the SDD and the corresponding detailed operating procedures. 
Each operating procedure outlined in the SDD should be sufficiently detailed to clearly identify the individual flow paths used, the instruments used to control these operations, and the proper sequence of steps to accomplish the operations. The operating stations where the procedures are performed also should be identified.

Each operating procedure outline preferably should be written in an itemized (step-by-step) format. Reference should be made to the system schematic diagram (component name and number) and to such tabular summaries and graphs of operating conditions as may be required.

Typical groupings of operating procedure outlines for a fluid system are provided below; however, these groupings may be altered, and others that may be unique to a particular system should be added to provide complete coverage of the operating procedures for that system.

4.6.1 Initial Fill. This outlines the prerequisites and those procedures required to prepare and initially fill the system. In the case of an auxiliary or service system, procedures for its use in the initial fill of the main heat transport system should be included.

4.6.2 Startup. This outlines the operations necessary to bring the system from the filled condition to a normal operating condition. Depending upon the particular system, several procedures generally will be necessary in this group, including system heatup and nuclear startup for the principal reactor plant systems.

4.6.3 Normal Operation. This outlines the procedures associated with normal steady-state, full-power, and reduced-power operation and design transient or maneuvering conditions. Operating condition envelopes showing the allowable operating ranges and appropriate limitations should be included.

4.6.4 Shutdown. This outlines the procedures for system shutdown, including shutdown to hot standby, shutdown and cooldown, establishment of refueling conditions, and the maintenance of elevated or reduced temperature shutdown conditions as appropriate to the specific design requirements.

4.6.5 Draining. This covers operations for draining the entire fluid system and portions of the system. The end condition of draining and constraints on operation should be specified.

4.6.6 Refilling. This outlines the steps for refilling a fully or partially drained fluid system. In the case of an auxillary or service system, procedures for the use of this system in refilling the main heat transport system should be included.

4.6.7 Infrequent Operations. This covers those operations which are used infrequently or under unique conditions, such as reactor plant operation with an isolated main heat transport loop. 
4.7 Casualty Events and Recovery Procedures (Section 5). This section identifies the possible casualty events that could affect the system and the protection provided against those casualties by the system design. It also outlines the system design features and recovery procedures which will mitigate the consequences of the casualties and restore the system and plant to a known, confirmed safe condition.

4.7.1 Casualty Events. A casualty event is defined as an abnormal system or plant condition which affects the safety, integrity, or proper functional operation of the system or plant; could produce system or plant degradation or affect personnel safety; and which requires action to restore the system or plant to a known, confirmed safe condition or to mitigate the consequences of the casualty event.

In this subsection, the casualty events which can be experienced by the system should be identified. Some examples of casualty events to be included are:

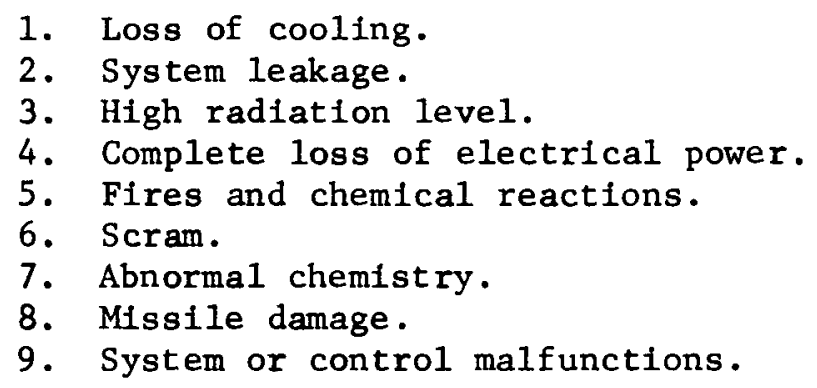

\subsubsection{Design Features to Mitigate Effects of Casualty Events.} This subsection should outline briefly the design features which provide protection and mitigate the effects of the casualty events. The instrumentation which discloses the casualty event and its location should be identified. Where appropriate, the resultant system performance characteristics and parameters under the casualty conditions should be provided.

4.7.3 Recovery Procedures. This subsection outlines the recovery procedures performed by plant operating personnel to restore the system or plant to a known, safe condition, prevent propagation of and mitigate the effects of a casualty event, and assure personne 1 safety. The specific instrument indications, alarms, or both, which signal the casualty event should be stated, and the applicable recovery procedure should be outlined. Any follow-up and diagnostic action necessary to identify the cause of the casualty and the required permanent corrective action also should be speciffed.

4.8 Maintenance (Section 6). This section defines the maintenance philosophy; outlines the procedures for corrective maintenance, preventive maintenance, and in-service inspection and surveillance; and identifies interfacing systems needed to support maintenance operations, as 
described in more detall in the following paragraphs. This section provides the basis for preparation of detailed maintenance procedures.

4.8.1 Maintenance Approach. This subsection defines the spectfic design approach that will be followed for system maintenance. Specific design philosophy taken from the SDD for a heat transport system is shown in Example 6 .

Routine maintenance activities must be performed during reactor outages. The system design will consider maintenance activities in the following order of preference:

-- adjust or repair in place.

-- repair components by contact maintenance to the extent permissible (consistent with personnel exposure and safety needs).

-- replace component with spare unit (and then repair and requalify the disabled unit).

-- remove component for decontamination/repair by contact maintenance and replace same component.

-- remote replacement of components.

-- repair components in place by remote maintenance (using manipulators and other remote-operated tools).

Example 6

4.8.2 Corrective Maintenance. This subsection outlines the procedures for placing the system in a condition sultable for corrective maintenance or replacement of the individual system components. It also identifies those special tools and equipment needed to permit performance of the maintenance operation, to maintain system cleanliness, and to maintain other specified conditions on the system and plant during the maintenance period. It references, but does not repeat, those system operating procedures in Section 4 of the SDD which are used to obtain the required system condition (such as system drainage). The design requirements that are imposed on interfacing systems to enhance maintenance capability should be defined. If another system is used for transporting a component outside the plant for repair, the appropriate reference to the SDD for that system should be included.

Individual corrective maintenance procedures should be outlined for each component of the system. This may be provided in tabular form if more convenient. Reference should be made to the component operation and maintenance manual (based on RDT F 4-20) for those detailed steps 
and procedures dealing with maintenance work within that component, such that there is no duplication of coverage.

4.8.3 Preventive Maintenance. An outline of preventive maintenance procedures for the system and each component in the system should be included. However, reference should be made to the appropriate component operation and maintenance manual for those detailed steps involving work within that component, such that there is no duplication of coverage.

4.8.4 In-Service Inspection. The conditions for performing inspection of the system during operation or shutdown should be defined. The system design features to accomplish the required inspections should be identified. Specific equipment and access needed for the inspections also should be identified.

4.8.5 Survel1lance. The necessary instrumentation for surveillance of the system and its components during the lifetime of the plant should be identified in this section.

4.9 Appendixes. The appendixes include reference lists, system drawings, parameter 1ists, equipment 1ists, and other essential material to present the complete design, which is not conveniently included in the previous text of the SDD.

The following are examples of typical materials to be included as appendixes.

4.9.1 References. Each SDD should have two reference lists. The first list should include references to that information which is an integral part of the SDD, such as design thermal transient data or seismic design data. The second list should cover those supporting analyses, evaluations, trade studies, etc., which provide background information but are not essential to define the selected design.

4.9.2 Parameters List. This includes the complete system and component operating and design parameters (pressure, temperature, flow, volume, size, capacity, materlal, etc.), and clearly distinguishes between the nominal operating and design parameters.

4.9.3 Typical Drawings. The following are typical drawings to be included as appendixes.

a. Process and Instrument Drawings. These are included in all fluid system descriptions and should show schematic representation of the system piping and instrumentation.

b. Schemat1c Drawings and Block Diagrams. These are included in SDD's for instrumentation and control systems and electrical systems. 
c. Hydraulic Profile Drawings. These are included where specification of the relative elevations of system components and piping is necessary to satisfy the system design or operating requirements.

d. Arrangement or Equipment Location Drawings. These are included where necessary to show the location and configuration of system components within the facility.

e. Piping Drawings. These drawings, preferable isometric drawings, are included for the principal fluid systems.

4.9.4 Instrument List. This list includes each sensing element, type, range, accuracy, set point, function (whether indicating, control, alarm, or combination of these), and where indicated (what pane1).

4.9.5 Valve List. This list includes individual valve function, size, type, pressure and temperature rating, American Society of Mechanical Engineers Code classification, operator requirement, and specification number.

4.9.6 Equipment List. This includes component name and number, major design parameters (e.g., capacity), and specification number.

\section{CONTENT OF OVERALL PLANT DESIGN DESCRIPTION}

The OPDD provides an overview and orientation of the various systems, structures, and facilities which comprise the plant, with an identification of the individual systems, their boundaries and interfaces, and the SDD's prepared to cover them. The OPDD should not include the extensive detail expected in the individual SDD's, but rather should provide concise descriptions to familiarize the user with the SDD structure and the overall functions, interfaces, and layout of plant systems, structures, and facilities.

The OPDD does not contain any technical information beyond that appearing in more detail in the specified individual SDD's, except for that covering those plant services and facilities which are not otherwise to be covered by SDD's.

5.1 Content. The OPDD presents a concise summary of the design and principal parameters of the overall plant; a definition of individual systems, facilities, and services composing the plant; the corresponding SDD assignments; and a brief description of ancillary services, facilities, and systems not otherwise covered by SDD's. Although no particular format is prescribed for the OPDD, the following information as a minimum shall be included and shall be organized for effective presentation, considering the complexity of the particular plant design:

1. Brief description of the overall plant complex, including the site, reactor and support buildings and facilities, 
and the location and arrangement of principal reactor coolant and steam cycle components and systems.

2. Principal design guidelines and criteria, and overall plant requirements.

3. Principal plant operating and design parameters.

4. Overall plant cycle diagram and heat balance.

5. List of all systems, services, and facilities comprising the plant, and the identification of corresponding SDD's and those areas for which no SDD's are required.

6. Descriptive paragraphs for each system and facility, concisely indicating its functions, princlpal requirements and parameters, and its boundaries and principal interfaces with other related systems and facilities, including simplified schematic diagrams where appropriate for clarity or to reduce extensive narrative.

7. Brief description of overall plant operating modes, including identification of principal control station locations. This section is not intended to be the location for overall plant operating procedure outlines, which should be included elsewhere appropriately in the SDD's. However, it should denote specifically in which SDD's these procedure outlines are located.

8. Brief description of plant maintenance requirements and capabilities, and the systems and facilities provided for maintenance.

9. Appropriate diagrams and drawings, including:

a. Site plan.

b. Composite reactor plant fluid system diagram.

c. Steam cycle diagram.

d. Electrical power distribution diagram.

e. Selected overa11 layout and arrangement drawings which show the orientation of principal plant components, systems, and factlities. 


\section{APPENDIX A}

DETAILED OUTLINE FOR HEAT TRANSPORT SYSTEM

1. FUNCTION AND DESIGN REQUIREMENTS

1.1 Functions

1.2 Process Requirements

1.3 Structural Requirements

1.3.1 Steady State

1.3.2 The rmal Transients

1.3.3 Seismic Design Requirements

1.3.4 Hypothetical Core Disruptive Accident

1.3.5 Natural Phenomena

1.3.6 Construction Material

1.4 System Configuration and Essential Features

1.5 Decay Heat Removal

1.6 Design Life

1.7 Design Safety Requirements

1.8 Maintenance

1.9 Surveillance and In-Service Inspection

1.10 Heat Transport System (HTS) Instrumentation and Controls

1.11 Interfacing Fluid Systems, Electrical Systems and Structures

1.12 Quality Assurance

1.13 Codes and Standards

2. DESIGN DESCRIPTION

2.1 Summary Description

2.2 Primary Sodium Loops

2.3 Secondary Sodium Loops

2.4 System Performance

2.5 Off-Normal Decay Heat Removal

2.5.1 Leak Within a Guard Vesse 1

2.5.2 Leakage from the Elevated Piping

2.5.3 Natural Circulation

\subsection{Detailed Primary Sodium Loop Description}

2.6.1 Primary Loop Arrangement

2.6.2 Primary Coolant Pump

2.6.3 Intermediate Heat Exchanger (IHX)

2.6.4 Isolation Valves

2.6.5 Check Valves

2.6.6 Primary Loop Flowmeter

2.6.7 Guard Vesse1s

2.6.8 Primary Loop Strainer 
RDT F 1-2T

PAGE 17

2.7 Detailed Secondary Sodium Loop Description

2.7.1 Secondary Loop Arrangement

2.7.2 Secondary Coolant Pump

2.7.3 Dump Heat Exchanger (DHX)

2.7.4 Secondary Loop Expansion Tank

2.7.5 Secondary Loop Valves

2.7.6 Secondary Loop Flowmeters

2.7.7 Secondary Loop Strainers

2.8 Preheating

2.9 Insulation

2.10 Piping and Penetrations

2.10.1 Primary Loop Piping

2.10.2 Secondary Loop Piping

2.10.3 Piping Penetrations

2.11 Leak Detection

2.12 Fire Protection

2.13 Sodium Auxiliary Requirements

2.13.1 Sodium Makeup and Leve1 Control

2.13.2 Sodium Filling and Draining

\subsection{Inert Gas Requirements}

2.14.1 Cover Gas Pressure Control

2.14.2 Cover Gas Feed and Vent for Filling and Draining

\subsection{Instrumentation and Control}

2.15.1 System Requirements

2.15.2 Component Requirements

\subsection{Interfacing Systems}

2.16.1 Service to be Provided by others

2.16.2 Principal Interfacing Requirements for Decay Heat Removal

3. SYSTEMS LIMITATIONS, SET POINTS, AND PRECAUTIONS

3.1 Operating Limits and Set Points

3.2 Precautions

4. OPERATION

\subsection{Introduction}

4.1.1 Operating Design Basis 
4.1.2 Operating Systems

4.1.3 Operator Functions

4.2 Normal Steady State Operation with Three Loops
4.2.1 Ful1 Power
4.2.2 Part Load
4.2.3 Hot Stanby
4.2.4 Refueling

4.3 Norma1 Non-Steady State Operation with Three HTS Loops

4.3.1 Transition from Refueling to Hot Standby Temperatures

4.3.2 Power Ascent from Hot Standby (Normal Startup)

4.3.3 Power Reduction to Part Load or Hot Standby (Normal Shutd own)

4.3.4 Scram

4.3.5 Temperature Reduction to Refueling Condition

4.3.6 Restarting HTS Pumps Following a Scram

\subsection{Infrequent Operation}

4.4.1 Preoperation Testing

4.4.2 System and Component Requalification

4.4.3 Activating and Deactivating a DHX Module

4.5 Preheating Operation

4.6 Two-Loop Operation

4.6.1 Isolated Loop - Primary and Secondary Fil1

4.6.2 Isolated Loop - Secondary Loop Partially Drained

4.6.3 Isolated Loop - Primary Loop Drained

4.6.4 Non-Isolated Primary Loop

\subsection{Primary Fill and Drain Operation}

4.7.1 Primary System Fil1

4.7.2 Normal Isolated Loop Fill

4.7.3 Normal Unisolated Loop Fill

4.7.4 Fill from Primary Overflow Tank

4.7.5 Reactor Vesse1 Fil1

4.7.6 Normal Isolated Loop Drain

4.7.7 Normal Unisolated Loop Drain

4.7.8 Drain to Primary Overflow Tank

4.7.9 Reactor Vesse1 Drain

4.7.10 Rapid Drain

4.7.11 Draining and Filling of Major Primary HTS Components

4.7.12 Guard Vesse1 Drain

\subsection{Secondary Fill and Drain Operation}


4.8.1 Inerting the Secondary Components and Piping

4.8.2 Secondary Loop Fill (Western Loop)

4.8.3 Filling the East or South Secondary Loop

4.8.4 Degassing the Secondary Loop

4.8.5 Venting the Fill/Drain Lines

4.8.6 Fill of a Single DHX Module

4.8.7 Drain of the Secondary Loop

4.8.8 Drain of a Single DXH Module

4.8.9 Rapid Drain of the Secondary Loop

4.8.10 Rapid Drain of a DHX Module

4.8.11 Rapid Drain of the Secondary Loop (Excluding the DHX's)

\subsection{Natural Circulation}

\section{CASUALTY EVENTS AND RECOVERY PROCEDURES}

5.1 Casualty Events

5.2 Design Features to Mitigate Casualty Events

5.3 Radiation Hazards to Personnel and Equipment

5.4 Gas Entrainment

5.5 Fire and Chemical Reaction

5.6 Missiles

5.7 Effect of Natural Elements

5.8 System Malfunctions

5.8.1 Reduction in Reactor Cooling

5.8.2 Increase in Reactor Coolant

5.8.3 Sodium Boundary Leak

5.8.4 Internal Leak in an IHX

5.8.5 Blockage or Fallure of the IHX Vent Line

5.8.6 Abnormal Chemistry

5.8.7 Sodium Freezing

\subsection{Component Malfunctions}
5.9.1 Primary Pump
5.9.2 IHX
5.9.3 Isolation Valves
5.9.4 Check Valve
5.9.5 Primary Flowmeter
5.9.6 Primary Piping Penetrations
5.9.7 Secondary Pump
5.9 .8 DHX
5.9.9 Secondary Valve
5.9.10 Expansion Tank
5.9.11 Secondary Flowmeter

\subsection{Recovery Procedures}

\section{MAINTENANCE}


6.1 HTS Maintenance Philosophy

6.2 Personnel Exposure to Radiation

6.2.1 Occupational Exposure Limits

6.2 .2 Sources

6.2.3 Radiological Zone Classifications

\subsection{Corrective Maintenance}
6.3.1 IHX
6.3.2 Primary Pump
6.3.3 Primary Isolation Valves
6.3.4 Primary Check Valve
6.3.5 Primary Flowmeter
6.3.6 Secondary Pump
6.3.7 DHX
6.3.8 Secondary Valves
6.3.9 Primary Sodium Boundary
6.3.10 Secondary Sodium Boundary in Containment
6.3.11 Secondary Sodium Boundary Ex-Containment
6.3.12 Primary Loop Strainer
6.3.13 Secondary Loop Strainer
6.3.14 Secondary Magnet Flowmeter
6.3.15 Secondary Venturi Flowmeter
6.3.16 Secondary Loop Expansion Tank
6.3.17 Pipe Hangers, Supports, and Snubbers
6.3.18 Piping Penetrations
6.3.19 IHX Bypass Flowmeter
6.3.20 Preheaters
6.3.21 Leak Detectors
6.3.22 Instrumentation
6.3.23 Bellows Seal

6.4 Preventive Maintenance

6.5 In-Service Inspection

6.5.1 HTS Sodium Boundary

6.5.2 HTS Cells and Pipeways

\subsection{Surveillance}

APPENDIXES
A. REFERENCES
B. DRAWINGS
C. PARAMETER LIST
D. EQUIPMENT LIST 
RDT F 1-2T

PAGE 21

E. LIST OF SDD's

F. INTERFACING SYSTEMS

G. LEAK DETECTORS

H. SEISMIC RESPONSE CURVES

I. INSULATION DATA

J. HTS INSTRUMENTATION 


\author{
APPENDIX B \\ DETAILED OUTLINE OF SECTIONS 1 AND 2 FOR REACTOR SYSTEM
}

1. FUNCTIONS AND DESIGN REQUIREMENTS

1.1 Functions

1.2 System Design Requirements

1.2.1 Configuration

1.2.2 Reactor Performance

1.2.3 Test Capability

1.2.4 The rmal/Hydraulic/Shielding

1.2.5 Mechanical and Materials

1.2.6 Design Load Conditions

1.2.7 Instrumentation and Contro1

1.2.8 Interfaces

1.2.9 Codes and Standards

1.2.10 Survelllance and In-Service Inspection

1.2.11 Quality Assurance

1.2.12 Reliability Assurance

1.2.13 Initial Installation

\title{
1.3 Component Design Requirements
}

1.3.1 Components* (other components would follow as 1.3.2, 1.3 .3 , etc.)

1.3.1.1 Configuration

1.3.1.2 Performance

1.3.1.3 Installation

1.3.1.4 The rmal/Hydraulic/Shielding

1.3.1.5 Mechanical and Materials

1.3.1.6 Design Life, Load Conditions, and Fluence Limits

1.3.1.7 Safety

1.3.1.8 Instrumentation

1.3.1.9 Interfaces

1.3.1.10 Operability

1.3.1.11 Maintainability

1.3.1.12 Codes and Standards

1.3.1.13 Surveillance and In-Service Inspection

1.3.1.14 Quality Assurance

1.3.1.15 Rellability Assurance

*Components logically fitting into the reactor system are fuel assembly, nuclear control system, reflectors, restraint mechanism, shielding, and core support structure, and depending on the design, in-core instrumentation (mechanical) may also be included. 


\subsection{System Safety Requirements}

1.4 .1

1.4 .2

1.4 .3

1.4 .4

1.4 .5

1.4 .6

1.4 .7

Qua1ity Standards

Rellability Assurance

Performance Standards

Records

Reactor Core Design

Power Oscillations

1.4 .8

Power Coefficient

1.4 .9

Instrumentation and Control

1.4 .10

Reactivity Control

1.4 .11

1.4 .12

1.4 .13

Off-Normal Decay Heat Removal

Fuel and Waste Storage

Release of Radioactivity

1.4 .14

Hypothetical Core Disruptive Accident

Cooling of In-Core Assemblies During Handing

\subsection{System Maintenance Requirements}

1.5.1 Design to Minimize Maintenance

1.5.2 Requirements for Special Tools and Equipment

1.5.3 Development of Maintenance Procedures

2. DESIGN DESCRIPTION

2.1 Summary Description

2.2 System Description

\subsubsection{Configuration}

2.2.2 Reactor Performance

2.2.3 Test Capability

2.2.4 The rmal/Hydraulic/Shielding

2.2.5 Mechanical and Materials

2.2.6 Design Load Conditions

2.2.7 Instrumentation and Control

2.2.8 Interfaces

2.2.9 Codes and Standards

2.2.10 Survelllance and In-Service Inspection

2.2.11 Quality Assurance

2.2.12 Reliability Assurance

2.2.13 Initial Installation

\subsection{Component Design Description}

2.3.1 Component (other components would follow as 2.3.2, 2.3 .3 , etc.)

2.3.1.1 Configuration

2.3.1.2 Performance

2.3.1.3 Installation

2.3.1.4 Thermal/Hydraulic/Shielding 
RDT $\quad F \quad 1-2 T$

PAGE 24

2.3.1.5 Mechanical and Materials

2.3.1.6 Design Life, Load Conditions, and Fluence Limits

2.3.1.7 Safety

2.3.1.8 Inst rumentation

2.3.1.9 Interfaces

2.3.1.10 Operability

2.3.1.11 Maintainability

2.3.1.12 Codes and Standards

2.3.1.13 Surveillance and In-Service Inspection

2.3.1.14 Quality Assurance

2.3.1.15 Reliability Assurance 